\title{
MULTICULTURALISMO SEXUAL: DIFERENCIA, DIVERSIDAD E IDENTIDADES SEXO-GÉNERO EN EL RÉGIMEN HETEROSEXUAL NEOLIBERAL
}

Catalina Diaz Espinoza 


\section{CATALINA DÍAZ ESPINOZA}

Lesbiana feminista antirracista y educadora popular en el "Preuniversitario Profesora Mara Rita. Escuela popular feminista", ubicado en la Casa Central de la Universidad de Chile; y en la "Escuela popular de español Joane Florvil" para mujeres haitianas en el Barrio Yungay, Santiago de Chile.

Coordinadora del proyecto del Fondo de Desarrollo Institucional 2016-2018 "Procesos Educativos de Integración de Identidades de Disidencia Sexual en Chile, Brasil y Argentina" del Ministerio de Educación de Chile.

Tesista de Licenciatura en Historia de la Universidad de Chile.

Hija de funcionaria pública y obrero portuario, nieta de mujeres fuertes pero olvidadas y abuelos empobrecidos del puerto de San Antonio. 


\section{MULTICULTURALISMO SEXUAL: DIFERENCIA, DIVERSIDAD E IDENTIDADES SEXO-GÉNERO EN EL RÉGIMEN HETEROSEXUAL NEOLIBERAL}

Desde que recibí la invitación realizada por la Vicerrectoría de Extensión y Comunicaciones para participar de esta versión feminista de la revista Anales de la Universidad de Chile, puedo reconocer que múltiples y variados fueron mis sentires: en primer lugar, entendí la invitación a escribir como un fuerte remezón a la toma de consciencia sobre el momento histórico que estamos viviendo, en el cual las demandas feministas, por siglos sub-sumidas al under político e intelectual, desprestigiadas de todo valor simbólico y teórico, son actualmente consideradas valiosas e innegables para el interés público y obligan a la Casa de Estudios más importante del país a tomar cartas sobre el asunto. Ya no sólo en materia de protocolos de actuación ante el acoso sexual sino también en relación a la producción teórico política que se elabora por sus miembros. En segundo lugar, la invitación a escribir en un contexto "académico" -yo sin serlo- me genera una segunda interpelación: reconocer la necesidad de vincular las producciones intelectuales que suceden al margen de la academia en diálogo con ella, como un diálogo conjunto que revitaliza el espacio académico y que amplía el campo de difusión activista. Me resisto a seguir en la categoría de sujeto de estudio porque ¡tengo mucho que decir! No escribo para acceder al magíster o contar con horas en ayudantías mal pagadas, escribo porque mi realidad me obliga a protestar por medio de la palabra. Si la academia es una de las instituciones históricamente conducida y controlada por los intereses androcéntricos, hoy podemos afirmar que estamos siendo testigos de su desestabilización, porque las mujeres aprendimos a escribir, a hablar, a denunciar y no es poco lo que tenemos que decir, pues estamos develando dos mil años de patriarcado. Por tanto, no está dentro de mis opciones, al menos, dejar de disputar ningún centro de producción de conocimientos, menos si es en un llamado a ser parte del boicot al heteropatriarcado colonial capitalista. Por esto y más, aprovecho la oportunidad de escribir este ensayo para dar cuenta de las reflexiones, tensiones y diferencias que habitan en el campo de producción teórico feminista en relación a la política multicultural de la sexualidad y el género en tiempos neoliberales.

Esta interpelación desde el mundo académico al activista es a su vez una oportunidad de entablar un diálogo franco -o al menos intencionar su apertura- para discutir sobre los problemas políticos que actualmente debatimos las feministas del cono sur latinoamericano, particularmente en torno a la diferencia sexual, la política 
sobre las identidades de género y la diversidad sexual. Pero antes, advierto a las lectoras que no hallarán aquí una oda al gay parade, al día del orgullo, la bandera arcoíris o el movimiento homosexual masculino. Muy por el contrario, en las siguientes páginas me gustaría invitarlas a re-pensar las posibilidades de comprender la identidad sexual en relación a los movimientos políticos, el contexto histórico y la construcción de subjetividades individuales y colectivas desde un enfoque feminista.

Con esto deseo señalar que la decisión de un enfoque feminista es una decisión política, porque me rehúso a hablar desde un enfoque de género debido a ciertas complejidades y contradicciones que me despierta esto último. Mientras el enfoque de género tenga la posibilidad de ser cooptado por el neoliberalismo patriarcal para despojarlo de su elemento político constitutivo, basado en la denuncia de la dominación de los hombres hacia las mujeres, me parece un término demasiado amplio y políticamente peligroso que deja una ventana abierta para que la hegemonía se apodere de nuestra lucha política. Con esto no quiero decir que la creación de la categoría de género (o su enfoque) no haya sido una revolución para los paradigmas de la producción teórica, en la construcción de conocimiento y la denuncia política al sistema heteropatriarcal capitalista en las décadas pasadas, sino que más bien busco comprender que con el transcurso del tiempo, desde su creación hasta nuestros días, este concepto ha ido quedando desprovisto de su finalidad política. Cuestión no menor, que me parece es parte de las artimañas que el sistema heteropatriarcal ha tenido en la ofensiva por capturar las críticas contra-hegemónicas. Reconozco y agradezco la vital importancia que este enfoque significó en las décadas de 1960-2000, sobre todo por los debates que permitió y la generación de toda una genealogía de pensamiento feminista que ha estremecido las convenciones tradicionales del capitalismo heteropatriarcal racista. También creo que el género como concepto y categoría de estudio e investigación sigue siendo una herramienta útil ${ }^{1}$, pero me niego a decir que miro el mundo desde un enfoque de género porque significa que estoy de acuerdo con la preexistencia natural de esta categoría en la organización social. Explicitar el enfoque feminista significa en parte rechazar la connotación natural que tienen las categorías de sexo-género. Ambas son construcciones sociales ${ }^{2}$. También creo que esta sobrevaloración de los enfoques de género corresponde a un excesivo consumo de las epistemologías del Norte. Espero que este escrito sea leído como una invitación a pensar nuestras

1. Para profundizar en esto puede verse Scott, Joan W. "El género: una categoría útil para el análisis histórico" en Lamas, Marta compiladora. "El género: la construcción cultural e la diferencia sexual”. PUEG, México. Pág.365-302.

2. Wittig, Monique. "La categoría de sexo" 1976-1982 en "Pensamiento heterosexual y otros ensayos". Ed. Egales, S.L. 2006, España. Pág.22. 
categorías de análisis más allá del psicoanálisis, más allá de lo queer y definitivamente, más allá de Foucault ${ }^{3}$. Un pensamiento lesbiano desde el Sur me obliga a reconocer el contexto geopolítico desde el cual se escribe. Hablar de identidad no sólo ha de contener una dimensión simbólica sino también una dimensión política, estructural, histórica y material. Una dimensión individual del sujeto y una dimensión colectiva de la comunidad, inmersa en cadenas de relaciones sociales complejas, para nada rígidas o estables.

Es por todo esto y más que declaro explícitamente la necesidad de producir nuestros conocimientos desde un enfoque feminista materialista e interseccional de las identidades (y sus opresiones), permitiendo denunciar teóricamente y con la misma complejidad la violencia que vivimos cotidianamente. Así no perderemos el fondo por el cual teorizamos y escribimos: necesitamos nombrar la violencia, comprender el origen de nuestra rabia, conceptualizar las contradicciones y reconocer que nuestros sentires tienen un origen social, cultural y político. Por tanto, agradezco a todas las feministas y lesbianas que me anteceden, a las que me han compartido tardes y noches de diálogo, preguntas y comprensión, por ayudarme a elaborar las ideas que aquí se esbozan y aclaro que no pretendo hablar por ninguna de ellas, sin embargo, reconozco con orgullo y mucho cariño que gracias a todas ellas es que puedo hablar.

Ahora bien, lo que me convoca a re-pensar (sí, una vez más) la existencia de los conceptos como diversidad sexual, identidad de género o diferencia sexual es la urgente necesidad de reflexionar sobre la fácil asimilación de algunas de sus definiciones en un contexto político multicultural de inclusión, que niega la dimensión política y reduce las categorías de identidad a un mero menú de consumo donde las minorías sexuales son exhibidas en el neoliberalismo. Quiero decir que conozco a algunas de las personas que están al interior de las instituciones promoviendo políticas de inclusión, que comprenden la discriminación y desigualdad y trabajan para acortar la brecha. Las conozco y agradezco el trabajo, sin embargo, zcuánto de esa política de inclusión sólo es un mitigante reformista que aplica sobre realidades individuales y no representa un cambio estructural de la violencia hacia las colectividades? Una de las características del multiculturalismo es justamente que entiende el "reconocimiento" o la inclusión en términos individuales y no colectivos. Por ejemplo, uno de los mecanismos más

3. Al respecto puede leerse la crítica que realiza Silvia Federici en la introducción de "Calibán y la bruja: mujeres, cuerpo y acumulación originaria", donde aclara que Foucault "está tan intrigado por el carácter 'productivo' de las técnicas de poder con las que el cuerpo ha sido envestido, que su análisis deja prácticamente fuera cualquier crítica de las relaciones de poder". "Calibán y la bruja: mujeres, cuerpo y acumulación originaria”. 2da edición. Puebla-Oaxaca: Tinta Limón, Pez en el árbol, Labrando en Común, 2015. Pág.33-34. 
utilizados por el multiculturalismo puede ser el sistema de becas o cupos de estudio que premian la diferencia en tanto individuo representante de su minoría, pero jamás se piensa dicha inclusión en términos de compensación política histórica al colectivo subalterno. El problema que han planteado las disidencias sexuales feministas en torno a la política de la inclusión y la diversidad sexual es ¿queremos ser incluidas en un sistema heteropatriarcal racista y capitalista? En medio de la imperiosa necesidad por "igualar la cancha" en materia de derechos hemos olvidado la macabra historia que habita al interior de esta cancha. Es necesario entonces encender las alarmas, las sospechas, ante esta política inclusiva que aparenta resolver los problemas en tiempos neoliberales y multiculturales. Es necesario retomar los análisis realizados por el feminismo materialista, que jamás conciben la disociación de lo simbólico con lo socio-político en la construcción de identidades y movimientos en torno a la diferencia sexual. Por último, este ensayo busca comprender la distancia que existe entre la diversidad sexual -o también conocido como movimiento LGBT'TI*- de los movimientos feministas. Este caso nos ayudará a comprender la ficción esencialista que existe en torno a la identidad que pretende una cierta unidad colectiva por el solo hecho de compartir prácticas, discursos o experiencias subalternas ${ }^{4}$.

\section{DIFERENCIA SEXUAL Y RÉGIMEN HETEROSEXUAL}

En un momento histórico en el cual el feminismo ha logrado ser instalado como un movimiento político vigente, necesario y capaz de generar agentes revolucionarias en todo el mundo, es que tanto sus conceptos, categorías y teorías son más utilizadas y referidas que nunca. Sin embargo, dichos conceptos provienen de distintas escuelas o genealogías de pensamiento feminista que no necesariamente presentan una homogeneidad o acuerdo político. Mucho más sincero es decir que hay tantos feminismos como feministas en el mundo. Cada mujer subvierte el orden establecido y resiste ante la violencia para poder existir con la mayor dignidad posible en un mundo que la aborrece y al mismo tiempo la necesita para mantenerse. No obstante, dicha resistencia ha sido convertida en un campo de disputas teóricas sobre el cómo y por qué de la violencia patriarcal. Algunas feministas aseguran que la diferencia sexual o identidad sexual constituye la realidad de las mujeres y los hombres. Entienden la existencia de ambos sujetos -hombres y mujeres- en función de experiencias corporales que desarrollan subjetividades en los cuerpos y

4. Serán empleados aquí los conceptos de subalternidad y hegemonía bajo la definición y propuesta de Antonio Gramsci en los Cuadernos de la cárcel, co-edición Editorial Era y Benemérita Universidad Autónoma de Puebla, $1^{a}$ ed. en español, México, 1999. 
mentalidades de las personas. Otras corrientes de pensamiento buscan distanciarse de las categorías esencialistas y naturalistas que reafirman la existencia de hombres y mujeres en función del sexo biológico o, si se prefiere, de las características psicológicas y físicas aportadas por el cuerpo sexuado. Una de estas corrientes feministas que busca comprender la diferencia sexual en contraposición a una fundamentación teórica esencialista, biológica o naturalista es lo que se conoce como la escuela del feminismo materialista. El punto central del feminismo materialista "radica en que ni los varones ni las mujeres son un grupo natural o biológico, no poseen ninguna esencia específica ni identidad que defender y no se define por la cultura, la tradición, la ideología, ni por las hormonas sino que simple y sencillamente, por una relación social, material, concreta e histórica" 5 . Puede reconocerse el pensamiento materialista como una comprensión estructural de la violencia que rechaza la preexistencia de la diferencia sexual bajo concepciones naturalistas o esencialistas. Dicha relación social es una relación de clase ligada al sistema de producciónreproducción, al trabajo y a la explotación de una clase por otra: la clase de los varones frente a la clase de las mujeres, en una relación antagónica que no puede ser reducida a una "guerra de sexos" ni al principio de "complementariedad", sino más bien a una contradicción cuya resolución significa la muerte de hombres y mujeres como clases sociales ${ }^{6}$. Algunas de las representantes del feminismo materialista son Monique Wittig, Nicole Claude Mathieu, Christine Delphy, Paola Tabet y Collete Guillaumin, y me atrevería también a añadir a algunas contemporáneas como Silvia Federici u Ochy Curiel. Se trata de mujeres que elaboran su teoría política feminista entendiendo la diferencia sexual no como un supuesto orden natural de la realidad sino como un entramado de relaciones políticas, económicas y socioculturales generadas a partir de la dominación de la clase hegemónica del hombre blanco heterosexual hacia la subalternizada clase de las mujeres, lesbianas y racializadas/os.

Ahora, bien puede surgir la duda: si las materialistas no creen en la existencia natural de hombres y mujeres, ¿por qué significar las clases sociales bajo las mismas categorías? Monique Wittig nos advierte que debemos tener mucho cuidado al distinguir entre las-mujeres (la clase dentro de la cual luchamos) y la-mujer, como el mito $^{7}$. Esto, ya que cuando asumimos que sexo o género son categorías en sí mismas preexistentes, estamos olvidando que su construcción ha sido para justificar la opresión. Categorías que al ser construidas, pueden también ser cuestionadas.

5. Curiel, Ochy; Falquet, Jules: "Elpatriarcado al desnudo. Tres feministas materialistas: Colette GuillauminPaola Tabet- Nicole Claude Mathieu”. Brecha Lésbica ed. 2005, Buenos Aires. Pág.8.

6. Idem.

7. Wittig, Monique, "No se nace mujer" en "Pensamiento heterosexual y otros ensayos". Ed. Egales, S.L. 2006, España. Pág.38. 
Monique Wittig explica esto diciendo que la opresión es la que crea el sexo cuando supone una división natural preexistente del mismo ${ }^{8}$. También señala, desde el enfoque materialista, que antes del conflicto (lucha de clases, en este caso) no existen categorías de oposición (mujeres definidas en torno a la oposición $=$ mujer en tanto no hombre) sino más bien categorías de diferencia, y sólo cuando la lucha estalla es cuando se manifiesta la violenta realidad de las oposiciones y el carácter político de las diferencias ${ }^{9}$. Al respecto, la autora nos devela cómo la hegemonía heterosexual construye realidades a priori que sostienen el statu quo de la desigualdad y opresión de las mujeres. Sintetiza al menos tres concepciones o argumentos que amparan la preexistencia del sexo.

En primer lugar, la metafísica, que señala que antes que todo hay sexos como dos categorías "innatas" de individuos con una diferencia constitutiva y que tiene consecuencias ontológicas (podríamos sumar aquí al pensamiento religioso como sistema de representación basado en la creencia: "y Dios creó al hombre y a la mujer"). En segundo lugar estaría la definición científica, que presupone que antes que todo hay sexos que son "naturalmente, genéticamente u hormonalmente" diferentes y que esta diferencia tiene consecuencias sociológicas ${ }^{10}$. En último lugar nos señala la filosofía marxista, que comprende que antes que todo hay una división natural del trabajo en la familia". "Una división del trabajo [que] en su origen no es otra cosa que la división del trabajo en el acto sexual"12. En esto, Wittig enfatiza que el conjunto de discursos del pensamiento de dominación es reforzado constantemente y oculta la realidad política de la subyugación de un sexo por otro, el carácter obligatorio de la categoría en $\mathrm{si}^{13}$.

Este pensamiento de dominación, categorizado por Wittig como el pensamiento heterosexual, es para ella la matriz de la dominación de la clase de los hombres frente a la clase de las mujeres, puesto que no sólo existe una dominación hacia las mujeres sino también porque se las ha convencido de que aquel es el orden natural de las cosas y no hay más realidades posibles, lo que Wittig señala como el carácter

8. Wittig, Monique, "La categoría de sexo" en "Pensamiento heterosexual y otros ensayos". Ed. Egales, S.L. 2006, España. Pág.22.

9. Ibídem, pág.23.

10. Cómo olvidar el pasado eugenésico de la ciencia, en la cual esta teoría jugó un importante rol para distinguir a los aptos de los ineptos, también en un ejercicio de oposición.

11. Véase: Delphie, Cristine "El enemigo principal" en "Por un feminismo materialista. El enemigo principal y otros textos. Ed. Lasal, 1985, Barcelona.

12. Ibídem, pág.25.

13. Idem. 
ineluctable de la heterosexualidad ${ }^{14}$. Es decir, la heterosexualidad es inherentemente obligatoria y coercitiva.

Ahora bien, si sexo y género son categorías que reafirman la diferencia sexual entre hombres y mujeres al interior del régimen heterosexual, ¿qué sucede con las colectividades que se identifican como no-heterosexuales? ¿Cuál es la relación entre el régimen heterosexual con sujetos que tienen prácticas sexuales no (re)productivas? ¿Cómo se entiende la diversidad sexual en el marco de la heterosexualidad neoliberal contemporánea? ¿Cómo son organizadas y representadas las prácticas y discursos de la disidencia sexual en el contexto multicultural? Estos son algunos de los problemas que busco abordar en el siguiente apartado, porque si bien "hombres y mujeres" existen en el marco del régimen heterosexual, sería poco verídico decir que dichas construcciones sociales no rigen también las prácticas, discursos y representaciones de las disidencias.

\section{MULTICULTURALISMO SEXUAL: ¿DE QUÉ DIVERSIDAD ESTAMOS HABLANDO?}

¿Cómo está representada la diversidad sexual hoy en el espacio público? ¿Es la diversidad sexual a priori un movimiento feminista? ¿Hay algún punto en común entre el feminismo y la diversidad sexual? Muchas veces tendemos a universalizar nuestras experiencias como totalizantes de la realidad. Como un ejercicio en contra de dichas generalizaciones debemos ahondar en algunas especificidades. Especialmente quienes nos reconocemos como lesbianas feministas olvidamos que muchas veces somos incluidas -con o sin nuestro consentimiento- bajo el paraguas de la diversidad sexual generalmente reducida a la sigla LGBT'TI* que aglomera en sus letras a varones homosexuales, lesbianas, transexuales, transgéneros, intersexuales y un asterisco que permite la posibilidad de seguir sumando identidades y letras.

Desde el surgimiento de los llamados nuevos movimientos sociales desde la década de 1970 en adelante, se abrió la llamada política de la identidad. Los estudios sobre la política de la identidad suelen definir que estos movimientos sociales se encuentran en función de experiencias compartidas en torno al género, raza u orientación sexual. Cabe destacar que no sólo se distinguen reunidos en torno a la diferencia sino también encontrados bajo la misma piedra angular de la violencia, mecanismos de exclusión, discriminación y maltrato.

Creo necesario señalar también que en cuanto al carácter de "nuevos" movimientos sociales existe un dejo de falta de rigurosidad, ya que en términos

14. Wittig, Monique, "Pensamiento heterosexual y otros ensayos”. Ed. Egales, S.L. 2006, España. Pág.51. 
de organización y visibilidad pública probablemente podemos rastrear a todos estos colectivos hacia comienzos del siglo XX (sobre todo en el caso de indígenas, afrodescendientes y mujeres), pero en términos de existencia es posible señalar que han estado desde los albores de la humanidad. Confundir el análisis o estudio de estos movimientos sociales con una datación temporal contemporánea, en parte, podríamos decir, es la punta del iceberg. Se ha tendido a pensar que las cuestiones que atañen a los grupos políticos organizados en torno a la identidad tienen un carácter contemporáneo, moderno o incluso, para algunos, posmoderno. Pero nada más lejos de esta ficción: el racismo, la lesbofobia o el sexismo no tienen ningún centímetro de novedad, puesto que la imbricación de los sistemas de dominación heteropatriarcal, colonial y capitalista sientan sus bases en la continuidad de más de cinco siglos de existencia ${ }^{15}$. Otra ficción discursiva y del pensamiento de dominación ${ }^{16}$ es aquella conceptualización de los grupos políticos organizados en torno a la identidad como minorías, ya que zqué tienen de minorías las mujeres, la población indigena, la afrodescendiente o la lesbiana? Aquella configuración de minoría en ningún caso atañe al número de integrantes de dicha colectividad (no es posible sostener que estos grupos sean minoritarios demográficamente) sino más bien a entender que lo minoritario es la proporción del poder a la que logran acceder los sujetos pertenecientes a dichas colectividades. Estos movimientos sociales organizados en torno a la identidad han conseguido instalar una demanda por el reconocimiento en al menos dos líneas: una simbólica, que apela a la ampliación del concepto de cultura; y otra histórico-política, que apela a un reconocimiento de las estructuras de dominación y mecanismos de exclusión.

Pero lo más valioso de esta política identitaria es la re-definición de la cultura, en la cual se considera la agencia política ${ }^{17}$ del sujeto subalterno, la que implicó una puesta en jaque a la tradición como cuestión de rígidas definiciones, como dice Raymond Williams: "la tradición no sería, necesariamente, el lugar de lo propio y lo auténtico, sino el resultado de una relación específica entre los sectores que detentan la hegemonía y aquellos que se encuentran subordinados al interior de esta; por ello advierte la necesidad de situar históricamente con el fin de identificar la función social que cumple y que puede ser de resistencia, pero también una cooptación o instrumentalización"18. Edward Said reafirma esta nueva concepción

15. Podemos señalar al menos su alianza conjunta en los albores de la colonización en Abya Yala.

16. Wittig, Monique, "Pensamiento heterosexual y otros ensayos" Ed. Egales, S.L. 2006, España. Pág.51.

17. Hall, Stuart. “QQuién necesita identidad?” en "Cuestiones de Identidad” de Stuart Hall y Paul du Gay compiladores. Ed. Amorrortu, Buenos Aires- Madrid, 1996. Pág.14.

18. Véase, Zapata Silva, Claudia. "Intelectuales indigenas en Ecuador, Bolivia y Chile. Diferencia, colonialismo y anticolonialismo" Santiago, LOM, 2016. Pág.39. 
del término cultura como un lugar de disputas ideológicas: "Lejos de constituir un plácido rincón de convivencia armónica, la cultura puede ser un auténtico campo de batalla en el que las causas se expongan a la luz del día y entren en liza unas con otras" ${ }^{\prime 19}$. Esta re-definición de la cultura nos permite relacionar la diferencia de grupos e identidades sexuales subalternas con las condiciones materiales e históricas que explican la opresión ejercida por los grupos hegemónicos. La cultura ya no es sinónimo de tradición o statu quo sino una construcción de relaciones sociales en disputa política. Esto queda muy bien explicado por Gloria Anzaldúa en su apartado Homofobia: miedo de ir a $\operatorname{cas}^{20}$, cuando describe que:

"la mayor parte de nosotras cree inconscientemente que, si mostramos ese aspecto inaceptable del ser, nuestra madre cultura-raza nos rechazará de plano. Para evitar ese rechazo algunas de nosotras nos amoldamos a los valores de la cultura, forzamos a las partes inaceptables a quedarse en las sombras. Lo que nos deja solo un temor -que nos descubran y que la Bestia-Sombra consiga liberarse de su jaula. Algunas de nosotras tomamos otro camino. Intentamos hacernos conscientes de la Bestia-Sombra, miramos fijamente el deseo sexual y el ansia de poder y la destrucción que vemos en su rostro, distinguimos entre sus rasgos la sombra que el orden imperante de los machos heterosexuales proyecta sobre nuestra Bestia. Con todo, algunas vamos un paso más allá: intentamos despertar a la Bestia-Sombra que llevamos dentro"21.

Esta relación con la "Bestia-Sombra" es lo que Anzaldúa reconoce como el miedo internalizado de ser diferente, que tiene al menos dos posibilidades de habitarnos: 1) ser identidades en reproducción de la subalternidad y con ello contribuir a la mantención del statu quo desigual; o 2) ser identidades en resistencia, despertando y removiendo el miedo. Podemos tomar decisiones en torno a la opresión que conlleva cada una de nuestras identidades, reproducir dicha violencia, asimilarnos al opresor, homogeneizarnos bajo la masa, aplicar reformas y profesar la igualdad universal; o tomar el segundo camino de la resistencia, que nos implica habitar y reafirmar en la diferencia, porque nuestra diferencia no es la definición de nuestra matriz metafísica natural, la diferencia se constituye en la disputa política contra la

19. Idem.

20. Anzaldúa, Gloria. "Borderlands/ La frontera: La nueva mestiza”. Ed. Capitán Sing Libros, S.L. Madrid, 2016.

21. Ibídem, pág.61. 
hegemonía heterosexual. Esta resistencia es la que nos invita a reflexionar en torno al "No queremos ser iguales".

Llegado este punto, es necesario añadir que dicha demanda por reconocimiento fue efectivamente acogida por la hegemonía, sin embargo, no bajo los términos políticos originalmente buscados sino como un modo de convertir la pelea por el reconocimiento en una oportunidad de cooptación en la cual se le desprovee de toda la matriz política para reducirla a un reconocimiento simbólico que se expresa a través de reformismos sutiles, que lejos de transgredir las duras estructuras de dominación, se burlan de las colectividades, reafirmando la violencia y desigualdad estructural. Esto no es nuevo, podemos ver a lo largo de la historia cómo el poder ha ido constantemente renovando sus bases y adaptándose a las exigencias a modo de aparentar desestabilizarse y ceder, cuando en realidad lo único que desestabiliza es la organización social, con maquillajes que mantienen inamovible el statu quo.

La apropiación de las luchas políticas por parte de la clase hegemónica es la manera que tiene el heteropatriarcado colonial capitalista de seguir existiendo: reinventándose. Esto es lo que hemos experimentado en las últimas décadas con la instalación de una política multicultural, la cual es definida por el sociólogo Charles Taylor como la forma en que el neoliberalismo entiende la diversidad cultural $^{22}$. El sistema neoliberal es progresista y no tiene reparos en reconocer nuevas identidades subalternas "diversas" mientras estas conserven la categoría de subalternas, el lugar marginal de la dominación y sean visibles en la medida en que consuman y sean ciudadanas del capitalismo. Un claro ejemplo son las campañas publicitarias de Benetton, que bajo el eslogan de United Colors of Benetton exhiben desmesuradamente fotografías "antidiscriminación" racial, de género y de clase, por medio de la construcción de una fachada inclusiva de una empresa crítica. Un eslogan que señala el problema de la discriminación en relación al subalterno y no en relación a la hegemonía. En vez de ver parejas lesbianas racializadas buscando ser incluidas en un sistema de desigualdades, podrían señalar quién es el causante de su subalternidad. Aunque, sabemos, eso implicaría condenarse a sí mismos. En el multiculturalismo, la cultura es un signo superficial en el cual se está dispuesto a aceptar la diferencia en tanto se mantengan e identifiquen como diferentes a las minorías políticas, las cuales se transforman en meros ornamentos que decoran el abanico de posibilidades, casi como una cuestión de alternativas que giran en torno a la hegemonía dueña de normalidad, en la cual la diversidad "enriquece" el mundo.

22. Véase Taylor, Charles. "El multiculturalismo y la «política del reconocimiento»". México, D.F: Fondo de Cultura Económica, 1993. 
La "diversidad", por tanto, es definida en torno a la persistencia de la desigualdad, no a la desaparición de las jerarquías sociales.

Ahora bien, me gustaría utilizar el ejemplo de la "identidad de género" para referirme al multiculturalismo sexual. Ha aparecido una teoría reconocida bajo el nombre de genderbread $^{23}$, en la cual se diferencia el sexo del género, la orientación sexual y la expresión de género para explicar la existencia de personas homosexuales, lesbianas y transgénero o transexuales. Entiendo que esta propuesta busque ser una herramienta pedagógica para explicar el significado de dichos términos. Sin embargo, no puedo omitir que me presenta una gran inquietud el hecho de disociar estos conceptos al interior del cuerpo en diferentes identidades o colectividades políticas.

En la definición del genderbread encontraremos que la categoría de sexo denominará nuestras características biológicas, como la genitalidad, en las cuales las posibilidades se reducen a hembras, machos e intersex (aunque esta última es casi nulamente reconocida); seguido del concepto de identidad de género, definido como la identidad auto-percibida, el "cómo nos sentimos en nuestro interior psicológico", que en el común de las ocasiones se reduce al binomio femenino o masculino; en tercer lugar, el concepto de orientación sexual, que busca dar cuenta de los deseos/ afectos que podamos expresar hacia otras personas, clasificando a la población entre lesbianas, homosexuales o bisexuales; y por último, expresión de género, que vendría a ser cómo somos "leídas" socialmente en la esfera pública ${ }^{24}$. Por ejemplo: mi sexo sería hembra; mi género, femenino; mi orientación sexual, lésbica; y mi expresión de género, mujer. En el caso de una lesbiana camiona ${ }^{25}$, su sexo es el de hembra; su género, el femenino; su expresión de género, masculina; y su orientación sexual, lesbiana.

Sin embargo, lo que oculta este simple esquema son las cuestiones que me preocupan. En primer lugar, que esta organización conceptual sólo organiza la existencia subalterna de las minorías sexuales, no registra a la hegemonía. Jamás se cuestiona el régimen heterosexual y es una nueva forma de re-conceptualizar

23. Véase la política “Genderbread” disponible en www.genderbread.org. Última consulta: lunes 23 de julio de 2018 a las 15:40 pm.

24. Idem.

25. Camiona: concepto proveniente del lenguaje popular para designar despectivamente a una lesbiana con fuertes caracteres masculinos. En otros países de América Latina se puede homologar a las categorías de "chonga", "marimacha", "butch", etc. Actualmente, esta categoría despectiva ha sido re-significada hacia una valoración positiva al interior de la comunidad lésbica para burlar la violencia lesbofóbica y a su vez, designar una de las tantas posibilidades de expresiones lésbicas que pueden existir. 
la diferencia sexual marginal que escapa de los binomios hombre-mujer. Esta propuesta desprovee de toda matriz material a las identidades sexuales o de género, dejándolas como meras opciones, variaciones, posibilidades o incluso en calidad de un repertorio posible y alternativo en la nueva realidad multicultural. Segundo, el sexo sigue siendo una categoría biológica natural-esencial en las personas. Es decir, todo lo que nazca con pene será reconocido como macho y todo ser que nazca con vulva será identificado como hembra. No se cuestiona en ningún instante la definición de dichas categorías desde una perspectiva política, en la cual una de las categorías -macho- domina al conjunto de seres asignados bajo la categoría de hembras. Es decir, el análisis sólo alcanza para comprender los sexos como posibilidades ontológicas y no como constructos sociales que justifiquen la dominación. Solamente se cuestiona la construcción social del género y se piensa, en el caso de los diagnósticos médicos como la disforia de género, que es una cuestión que puede ser solucionada a través de un ajuste o modificación para que el sexo (caracteres biológicos) concuerde con el género (caracteres socioculturales). En tercer lugar, la identidad como acto performático que sólo necesita de la "auto-percepción" es una comprensión obsoleta del sujeto. El proceso de auto-percepción es una de las tres dimensiones que constituyen la identidad política según la antropóloga argentina Claudia Briones, quien dice que se necesitan a lo menos tres elementos para constituir una identidad: 1) la auto-percepción, 2) sentido de pertenencia con la comunidad a la cual apela tu identidad y que se te reconozca como parte de ella y 3 ) un contexto histórico político que permita entender dicha identidad. Basándose en un planteamiento de Marx en El Dieciocho Brumario de Luis Bonaparte, Briones afirma que: "Los sujetos se articulan como tales a partir de un trabajo de identificación que opera suturando identidades personales y colectivas (para sí y para otros), pero no la hacen simplemente como a ellos les place, pues su trabajo de articulación opera bajo circunstancias que ellos no han elegido" ${ }^{26}$. Un ejemplo de esto sería que aunque yo quisiera llamarme a mí misma mujer blanca heterosexual porque "así me siento y auto-percibo", aquella apreciación no pasaría de ser un retrato eurocéntrico mal dibujado de mí misma o la clara intención de dejar de pertenecer a la clase oprimida, ya que bien, ¿quién podría querer serlo? Pero no basta con el solo hecho de explicitar mi deseo o sentimiento de querer ser una mujer blanca heterosexual, ya que no seré reconocida socialmente como tal y no comparto una historia política con dicha colectividad, que vendría siendo la historia de la hegemonía privilegiada. En el caso de que este mismo ejercicio me predispusiera a identificarme con otra

26. Briones, Claudia. "Teorías performativas de la identidad y performatividad de las teorías". Tabula Rasa, No.6, enero-junio 2007, pág.59. 
categoría subalterna, como mujer negra, ya no sólo estaríamos en presencia de un retrato desfigurado de mí misma sino también de un acto de apropiación política, como en reiteradas ocasiones sucede con la identidad de género.

Un cuarto elemento que me parece preocupante del multiculturalismo y la categoría de identidad de género es la posibilidad de re-ajustar la discordancia con el género asignado por medio de intervenciones o tratamientos médico-farmacéuticos. Esto, no porque tenga una concepción purista del cuerpo sino porque dicha regulación patologizante busca que todas las identidades, por muy diversas o contrahegemónicas que parezcan, sean re-organizadas bajo el régimen heterosexual. Creer en la posibilidad de separar la identidad de género de la orientación sexual no es más que un eufemismo y una práctica de regulación multicultural y heterosexual, que implica la imposibilidad de que dos mujeres sean lesbianas y un reconocimiento del deseo lésbico. Para el sistema es mucho mejor si una de esas dos mujeres transita y se reconoce desde la masculinidad para no alterar la suposición de heterosexualidad. La identidad de género nos re-organiza la orientación sexual para que no abandonemos la heterosexualidad. La identidad de género, en este sentido, subyuga y despolitiza la orientación sexual, releva al deseo a un plano íntimo, capaz de ser deconstruido hacia cualquier lado mientras devenga heterosexual, independiente de las socializaciones e invisibilizaciones históricas de las mujeres y de las lesbianas.

Y por último, a esto debemos sumar además que aunque exista un tercer sexo o diez posibles identidades de expresión de género, el problema va a seguir siendo la dominación ${ }^{27}$ y la jerarquía que establece siempre en último lugar el valor simbólico y político de las mujeres como clase social, o de lo que culturalmente es asociado a la femineidad, como es el caso de mujeres trans y travestis. Este modo es lo que Nicole Claude Mathieu llama forma de aprisionar a los tercer sexo/género con el fin de que no subviertan e incluso que confirmen la eficiencia social de la bicategorización ${ }^{28}$. Sobre el recambio de roles, bell hooks ha afirmado que algunas feministas burguesas pretenden pasar por avanzada política cuando acceden a mecanismos de productividad históricamente reconocidos como masculinos y señala que:

"La inversión no facilita el paso a otra clase de estructura. ¡El reformismo le viene bien a todo el mundo! El orden burgués, el capitalismo, el falocentrismo

27. Mathieu, Nicole- Claude. "IIdentidad sexual/sexuada/de sexo? Tres modos de conceptualización de la relación sexo género. En "El patriarcado al desnudo. Tres feministas materialistas: Colette Guillaumin- Paola Tabet- Nicole Claude Mathieu” compilado por Ochy Curiel y Falquet, Jules, Brecha Lésbica ed. 2005, Buenos Aires. Pág.168.

28. Idem. 
son capaces de integrar tantas feministas como sea necesario. En la medida en que esas mujeres se convierten en hombres, a fin de cuentas sólo significan unos cuantos hombres más. La diferencia entre sexos no reside en si se tiene o no pene, sino en si se forma parte o no de la economía fálica masculina"'29.

Hay dos grandes problemas aquí: por una parte, el régimen heterosexual que puede admitir variabilidades en el plano superficial -performático- de la identidad en términos de maleabilidad y expresión alternativa, siempre y cuando no se abandone la heterosexualidad; en consecuencia, el segundo problema es la dominación de una clase por otra en la relación jerárquica entre varones y mujeres. Es más fácil corregir la identidad de género y permitir un deseo "libre" que generar una identidad política sexual. La identidad de género como categoría considera un "convencimiento" del subalterno de querer ser corregido. Hemos interiorizado la misoginia y la auto discriminación que nos hace pensar que estamos imperfectas y que podemos llegar a corregir el error de nuestra imperfección, creyendo que luego de la corrección podremos habitar más felices en el heteropatriarcado capitalista, lo que es una ficción puesto que la desigualdad y la violencia no serán resueltas por el solo hecho de reconocer una diversidad de identidades sexo-género. En cambio, la orientación sexual, el deseo no-heterosexual no puede ser corregido, al menos no sin recurrir a la violencia. El nuevo problema de la política de la identidad es el multiculturalismo, que reconoce simbólicamente y regula por medio de la medicina las identidades sexuales bajo cánones de subyugación. Esto me hace pensar que sin importar lo que sintamos en nuestro interior, todo el problema sigue radicando en el lugar que ocupamos en la escala de la desigualdad. Con esto jamás estaría pensando en poner en duda el sentir discordante del sexo o el género, pues lo anormal es sentirse a gusto con dichas categorías. Tampoco quiero relativizar la experiencia de personas trans sino más bien criticar la categoría de análisis que busca regular los cuerpos, las experiencias y discursos no heterosexuales bajo la política de la identidad de género. Aunque nos asimilemos en identidades de géneros, en nuestro interior seguimos teniendo las huellas de la violencia. Entiendo también el deseo de querer escapar de las representaciones sexo-género en las cuales hemos sido obligadas a vivir (como hombres o mujeres), pero dicha fuga no puede hacerse a través del recambio de roles o la asimilación con la hegemonía, porque al asimilarnos no escapamos de la escala de desigualdad. Una propuesta revolucionaria debiera plantear destruir la hegemonía y transformar las estructuras de convivencia en la sociedad.

29. Antoinette Fouque, en hooks, bell: "Mujeres negras: Dar forma a la teoría feminista", en Otras inapropiables, Ed. Traficantes de Sueños, Madrid, 2004. Pág.40. 


\section{CONCLUSIONES}

Retomo la pregunta: ¿queremos ser incluidos en un sistema neoliberal heteropatriarcal racista? ¿Queremos ser parte -voluntariamente- de la cadena de explotación? $¿$ Queremos ser reconocidos en tanto sujetos subalternos mientras no desafiemos la alteridad? No, no queremos ser oprimidos y cualquier intento por mantener las estructuras de poder ha de ser completamente rechazado. Muy por el contrario, lo que buscamos es tener incidencia en el espacio público, acceder a la versión solidaria de la modernidad que entiende de manera igualitaria nuestras existencias. Y no sólo las mujeres y lesbianas quisiéramos habitar en dicha igualdad, también con nosotras van muchos hombres empobrecidos, racializados y explotados por la hegemonía blanco burguesa, y también otras colectividades como las travestis, que pasaron a la historia sin nunca estar en ella, subyugadas ante la categoría contemporánea de trans/género/sexual, cuestión que no voy a profundizar acá, mas no podía dejar de mencionar.

Las feministas han sido enfáticas en criticar la ficción romántica que hay detrás de la suposición universal de igualdad y ¿cómo no estar de acuerdo? Voy a poner una experiencia como ejemplo. Hace un par de años recuerdo estar detenida en una jaula (tan miserable espacio ni siquiera podría calificarse como calabozo) en la $1^{\circ}$ comisaría de Santiago Centro (Santiago, Chile) junto con dos compañeras travestis y mi novia lesbiana camiona. Más tarde llegó a la misma jaula Nicolás Martí, un hombre afroperuano detenido por vender comida en la calle. En dicha jaula estábamos dos lesbianas, dos travestis y un afroperuano. Y pese a ser todas parte de una minoría política, la detención misma tenía serias diferencias jerárquicas. Mi novia estaba esposada (tenía ambas manos esposadas juntas), Nicolás también estaba esposado, pero sólo una de sus manos estaba atada por medio de la esposa a la reja de la jaula, quedando con el brazo extendido de manera vertical y sin posibilidad de movimiento. Mi novia podía desplazarse por la jaula cuando la ayudábamos a levantarse, puesto que además de estar esposada también tenía serias contusiones producto de golpes efectuados por la policía y shock postraumático por asfixia (asfixia también generada en la detención por la policía). Tanto Nicolás como mi novia fueron juzgados bajo otras normas policiales, ya que a Andy se le puso en duda todo el tiempo su nacionalidad chilena, le pidieron el carnet en un sinnúmero de ocasiones, buscando encontrar irregularidades migratorias. Lo mismo en el caso de Nicolás, quien decía tener sus documentos al día aunque la policía insistiera en llamar a las oficinas de migración. En la misma jaula, las dos compañeras travestis fueron expuestas a ser tratadas bajo su identidad legal masculina (nombres de hombre), registros corporales irregulares y ser objeto del fetiche y burla de toda la comisaría, quienes iban a observar y conversar con ellas en un claro acto humillante, 
señalando si eran o no bonitas, si parecían más o menos mujeres, etc. En mi caso, fui la que gozó de más privilegios de desplazamiento, respeto identitario y menor violencia física. Sin embargo, no me salvé de ser negada a mis abogadas, familiares y compañeras de protesta que aguardaban nuestra salida de la comisaría, en un acto constante de vigilia, además de ser manoseada por un policía que esposada me llevó al baño. En medio de las conversaciones que sucedieron en la jaula estaban el miedo colectivo a que las compañeras travestis fueran llevadas al calabozo de varones para pasar la noche, el estado de salud de mi novia y la persecución sobre el estado migratorio de Nicolás Martí. En ello, Nicolás ofreció ayuda para cuidar a las compañeras travestis en caso de ser llevadas al calabozo de hombres. Un pequeño gran gesto de solidaridad entre oprimidos.

Éramos cinco detenidos, cuatro por manifestarnos contra la violencia machista, uno por trabajar. Pese a no haber hecho daño o cometido un crimen, todos teníamos miedo por la situación de inferioridad en la que nos encontrábamos. El miedo colectivo: la inseguridad de estar en las jurisdicciones de la policía de Estado cuando no eres heterosexual. Finalmente, un abogado del Instituto Nacional de Derechos Humanos logró sacarme a mí y a las compañeras travestis. Mi novia, en cambio, tuvo que pasar la noche y al día siguiente ser procesada en Fiscalía. Una vez allí, cuando tuvo la oportunidad de conversar con un defensor público sobre los motivos de su detención (ella explicó que fue por discriminación, por ser, entre todos los manifestantes, una lesbiana racializada), el defensor público le respondió "que eso era imposible, ya que todos somos iguales en la calle y ante la ley". Ahí, en aquella experiencia -por nombrar una entre montañas de episodios que podrían servir de ejemplos-, quedó manifiesta la ficción y contradicción de la supuesta igualdad universal de los sujetos. No somos iguales. Y aunque seamos conscientes de ello, de aquella violencia, de la desigualdad y el dolor, también insistimos en la resistencia por nuestra dignidad y un lugar en el espacio público.

Como feministas, no buscamos detentar el poder. Esta no es una lucha por un recambio de roles, es una lucha por erradicar la violencia patriarcal y es una lucha a sangre, porque nos hacen cargar en la espalda las cicatrices de los nombres de nuestras compañeras muertas y con ello el dolor por su muerte. Es por esto último, por ser esta una lucha a sangre, que tomo el atrevimiento de señalar que cualquier esfuerzo por detentar el poder (en lo público o lo privado) no merece ser llamado feminismo. Con esto no estoy diciendo que debemos estar en contra de las mujeres y lesbianas que ocupen cargos de dirección o de responsabilidad en sus trabajos, organizaciones o en el hogar. Estoy hablando de las ansias de poder, de detentarlo para dominar. De lo que estoy en contra es que aquellas mujeres sean utilizadas como ejemplos o porta estandartes de la equidad y resolución del problema político por estar en dichos cargos directivos. Estoy en contra de que aquella representación de 
acceso o equidad sea la finalidad de nuestro movimiento. El fin de nuestro quehacer feminista ha de ser la erradicación de la violencia machista, del régimen heterosexual, el colonialismo y la pobreza de todas las especies que habitamos el planeta. ¿Utópico? Sin lugar a dudas. Utopía que al considerarse como tal, evidencia la magnitud del problema: ¿cómo va a ser utópico dejar de morir -y vivir- a manos y voluntad de los hombres? Con esto no busco impacientar a las lectoras, la utopía no hace de nuestra lucha un continuo infinito, ya que ha de tener fin el día que erradiquemos los contratos sociales que mantienen la dominación de la clase de los hombres por sobre la de las mujeres. Esta utopía que imaginamos está por venir, alimenta nuestro activismo y despierta nuestra rabia. Rabia que es uno de los agentes más movilizadores a la hora de despertar consciencias y activar, accionar. Convertir el verbo en acción del discurso a la praxis. No todo pasado fue mejor: tenemos un futuro por delante y la posibilidad de construirlo es concreta, está en nuestro poder individual y colectivo desafiar la hegemonía, ya que si hablamos con franqueza, su poder sólo se sustenta en la ficción de inferioridad que hemos interiorizado como natural. No es natural el racismo, no es natural el género, el sexo, la diferencia sexual, la heterosexualidad o la pobreza. Todos son constructos sociales con implicancias emocionales y materiales. Pero tenemos el poder de sentir otras cosas, de relacionarnos de otras formas. Es, sin lugar a dudas, un desafío a nuestras creatividades. Pensar un mundo nuevo significa explorar nuevos sentires, definiciones, capacidades y discursos. 


\section{REFERENCIAS}

Anzaldúa, Gloria. "Borderlands/ La frontera: La nueva mestiza". Ed. Capitán Sing Libros, S.L. Madrid, 2016.

Briones, Claudia. "Teorías performativas de la identidad y performatividad de las teorías". Tabula Rasa, No.6, enero-junio 2007, pp.55-83.

Delphie, Cristine. "El enemigo principal" en "Por un feminismo materialista. El enemigo principal y otros textos. Ed. Lasal, Barcelona, 1985.

Federici, Silvia. "Calibán y la bruja: mujeres, cuerpo y acumulación originaria". 2da edición. Puebla-Oaxaca: Tinta Limón, Pez en el árbol, Labrando en Común, 2015.

Gramsci, Antonio. "Cuadernos de la cárcel". Co-edición Editorial Era/Benemérita Universidad Autónoma de Puebla, $1^{a}$ ed. En español México, 1999.

Hall, Stuart. “¿Quién necesita identidad?” en “Cuestiones de Identidad” de Stuart Hall y Paul du Gay compiladores. Ed. Amorrortu, Buenos Aires- Madrid, 1996.

hooks, bell. "Mujeres negras: Dar forma a la teoría feminista", en Otras inapropiables, Ed. Traficantes de Sueños, Madrid, 2004.

Mathieu, Nicole- Claude. "¿Identidad sexual/sexuada/de sexo? Tres modos de conceptualización de la relación sexo género. En "El patriarcado al desnudo. Tres feministas materialistas: Colette Guillaumin- Paola Tabet- Nicole Claude Mathieu" compilado por Ochy Curiel y Falquet, Jules. Brecha Lésbica ed. 2005, Buenos Aires.

Taylor, Charles. "El multiculturalismo y la «política del reconocimiento»". México, D.F: Fondo de Cultura Económica, 1993.

Wittig, Monique. "Pensamiento heterosexual y otros ensayos" Ed. Egales, S.L., España, 2006.

Zapata Silva, Claudia. "Intelectuales indigenas en Ecuador, Bolivia y Chile. Diferencia, colonialismo y anticolonialismo" Santiago, LOM, 2016. 